\title{
Lettuce growth in extreme conditions
}

\author{
Borja Slamic ${ }^{1}$, Tjasa Jug ${ }^{2 *}$ \\ ${ }^{1}$ Nova Gorica Gymnasium, Delpinova street, Nova Gorica, Slovenia, ${ }^{2}$ Chamber of Agriculture and Forestry of Slovenia, Nova Gorica Institute \\ for Agriculture and Forestry, Pri hrastu, Nova Gorica, Slovenia
}

\section{A B S T R A C T}

\begin{abstract}
Over-fertilization is one of important environmental problems, but also affects plant nutritional status. To investigate the influence of over-fertilization on leaf mineral content, lettuce was hydroponically grown at higher nutrients concentrations. The experiment revealed no significant differences in leaf mineral content and root length between treatments, but we have observed much bigger variability of data at the lowest concentration. Similar trend has been observed comparing mobilities: more nutrients there are in a solution, significantly smaller the variability between plants is. Obviously, plants need to compete between each other at lower nutrients availability for their uptake, which increases variability, but not at higher.
\end{abstract}

Keywords: Nutrients; Lettuce; Hydroponics; Mobility

\section{INTRODUCTION}

Fertilization practices unfortunately often lead to overfertilization (Vitousek et al. 2009), at least in smaller system such are gardens. It might bring some advantages, especially with relatively fast growing crop as lettuce, but there are many disadvantages too, since excessive nutrients are washed into rivers and streams or they remain in soil. It might not be such a problem in big, intensive systems, where every unnecessary cost is eliminated, so rational amounts of fertilizers are applied. But what about small surfaces? There are many studies reporting that gardens are over fertilized due to two reasons: first because they are usually smaller and you don't need the amount of the fertilizer you usually bought and the second is human nature: as we like to give candies to the kids, in the same way we like to (over)fertilize our plants. There might be even third reason - most of the guidance have been prepared decades ago, before the "times of abundance". We probably should now look at the guidelines from the perspective of too many nutrients and not too little?.

However, information on lettuce response to high supply of other nutrients is scarce (Albornoz and Heinrich Lieth 2015; Andriolo et al. 2005) and are mostly dealing with only one element change: phosphorous (Johnstone et al.
2005; Soundy et al. 2001b; Soundy et al. 2001a; Azcón, Ambrosano, and Charest 2003; Santos et al. 2004), nitrogen (Soundy et al. 2005; Azcón, Ambrosano, and Charest 2003) or organic fertilizers (Papathanasiou et al. 2012; Thorup-Kristensen 1999; Thorup-Kristensen 2006).

Several studies on lettuce already suggest the rationalization of the use of fertilizers by half, since no statistical differences between treatments regarding growth parameters have been observed when decreasing the nutrients (Cometti et al. 2008; Maruo et al. 2002; Chen et al. 1997). Chen et al. 1997 show that it is possible to reduce the concentration of the nutrient solution to levels as low as $10 \%$ of the original ionic strength of the solutions commonly used in hydroponic crops in recirculating systems, without incurring in productivity loss.

Ünlükara et al., 2008 has studied the response of lettuce to salinity of irrigation water and confirmed that it is moderately sensitive to salinity, but the results are variety specific. Anyway they have focused on salinity induced by chlorides and sulphates and not nutrients in general. On the other hand, Andriolo et al., 2005 and Albornoz and Heinrich Lieth, 2015 reported reduction of fresh yield and plant growth at higher salinity levels at systemically changing total nutrient concentrations. The leaf mineral content increased for several macronutrients (N, P, S and $\mathrm{Mg}$ ) with increasing

\footnotetext{
*Corresponding author:

Tjasa Jug, Chamber of Agriculture and Forestry of Slovenia, Nova Gorica Institute for Agriculture and Forestry, Pri hrastu 18,5000 Nova Gorica, Slovenia. Phone: +38653351224, E-mail: tjasa.jug@go.kgzs.si 
concentration of nutrients in the root zone in aeroponic experiment (Albornoz and Heinrich Lieth 2015), while in a hydroponic experiment performed by Andriolo et al., 2005, mineral content in leaves was not studied.

The experiment reported in this article studied the response of lettuce plants to balanced increases in nutrients supplied to the root zone in a hydroponic system. The objective of this study was to determine the effect of various concentrations of micro and macro nutrients on mineral content of lettuce plants.

\section{MATERIALS AND METHODS}

Plants of Latuca sativa cv. Gentilina (PRO. S. O. L.) were grown directly from the seeds in three separate NTF hydropo nic systems with continuous flow rate of 3 $\mathrm{m}^{3}$. Rock wool was used as a substrate. Roots were fully submerged and water level was kept constant by daily monitoring. Plants were exposed to natural day/night light conditions, daily and night average temperature were 28 and $22{ }^{\circ} \mathrm{C}$ respectively.

For the experiment, commercial nutrients were used according to the manufacturer's instructions: in L system double dose, in $\mathrm{M}$ normal dose and in the $\mathrm{R}$ half dose every 2 weeks till harvest. Amount of added nutrients in the $\mathrm{R}$ hydroponic system at the end of experiment were $330 \mathrm{ppm} \mathrm{K}, 70$ ppm Mg, 126 ppm Ca, 335 ppm N, 165 ppm $\mathrm{P}$ and $390 \mathrm{ppm} \mathrm{S}$ which is close to optimal values defined by Enzo et al., 2001.

Mature leaves were taken for analysis. Leaf analyzes have been performed after incineration of leaf sample at $550^{\circ} \mathrm{C}$. Ashes have been diluted in 0,3 $\mathrm{M}$ hydrochloric acid (ISO 6869). For phosphorus analysis, samples were treated with molibdovanadate, according ISO 6491, while potassium, magnesium, calcium, manganese, iron, copper and zinc have been determined with atomic absorption according to ISO 6869. The same methods were also used for determination of the nutrients in the hydroponic solution. Leaf nitrogen has been analyzed according to Kjeldahl method.

Statistics has been performed by Gnumeric. Different treatments were assessed according to $t$ test.

\section{RESULTS AND DISCUSSION}

The final nutrient values in a hydroponic solutions (Table 1) were high already in the system with the lowest nutrient status $(\mathrm{R})$ and at the upper level of commercial recommendations (Smart Fertilizers 2016). Measurement of calcium into the hydroponic solution at the end of experiment reveals that concentrations in $\mathrm{L}$ and $\mathrm{M}$ system are similar, which additionally proved that we worked in the extreme, and calcium had due to high concentrations precipitated (Schwarz 2012).

Regardless the extreme conditions, hydroponic solution was obviously still well balanced (Samarakoon, Weerasinghe, and Weerakkody 2006), and no visual plant disorders appeared. Nevertheless, as plant analysis should be early indicator of nutrients imbalance, it was unexpected that no important differences in leaf mineral content between systems have been observed (Figs. 1, 2) although it is in agreement with Albornoz and Heinrich Lieth, 2015 for K and Ca. For N, P, $\mathrm{S}$ and $\mathrm{Mg}$ they have reported statistically significant general increase, although not for every concentrations.

Although differences in crop weight between the systems were not significant (data not shown), we observed difference between systems regarding the length of roots. Average root length didn't show significant difference between systems, but in the system with the lowest dose of nutrients, variability of the results was the biggest (Fig. 3). Root lengths of lettuce have already been studied although results are confronting: some studies report root length

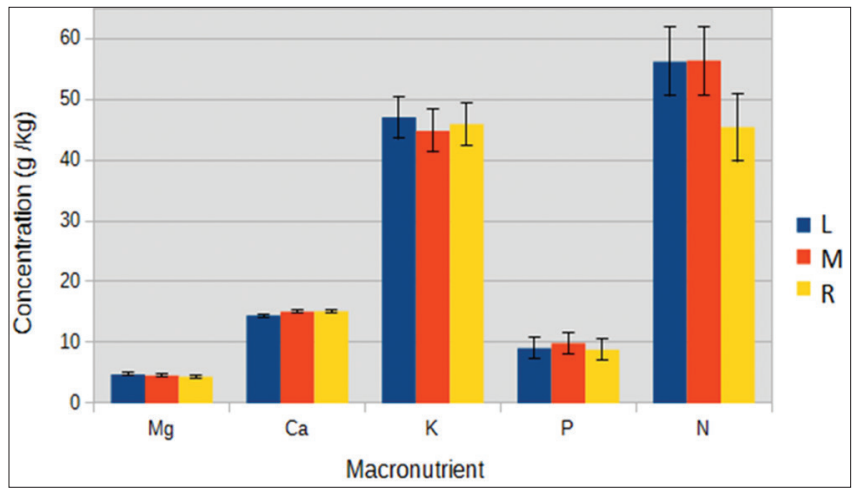

Fig 1. Nutrient mobility of macronutrients at different nutrient concentrations in hydroponic solution $(R=$ lowest $(1 / 2 M), M=$ medium, $L=$ highest $(2 M)$ ).

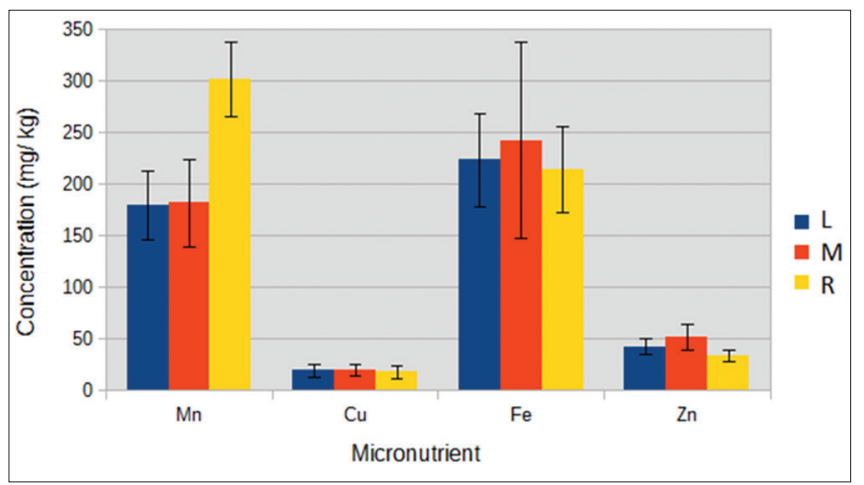

Fig 2. Nutrient mobility of micro nutrients at different nutrient concentrations in hydroponic solution $(R=$ lowest $(1 / 2 M), M=$ medium, $L=$ highest $(2 M)$ ). 
to be correlating with nutrient variability (Albornoz and Heinrich Lieth 2015; Soundy et al. 2005) and some not (Soundy et al. 2001b; Soundy et al. 2001a), depends on nutrient and variety.

Surprisingly, no study has reported increased variability at lower nutrient concentrations, although interpretation seem intuitive: plants need to compete between each other for nutrients if resources are scarce.

If we take into account concentration of the nutrients in the hydroponic solution and we calculate mobility for each system (mobility $=$ concentration of nutrient in plant tissue dry weight divided by concentration in hydroponic

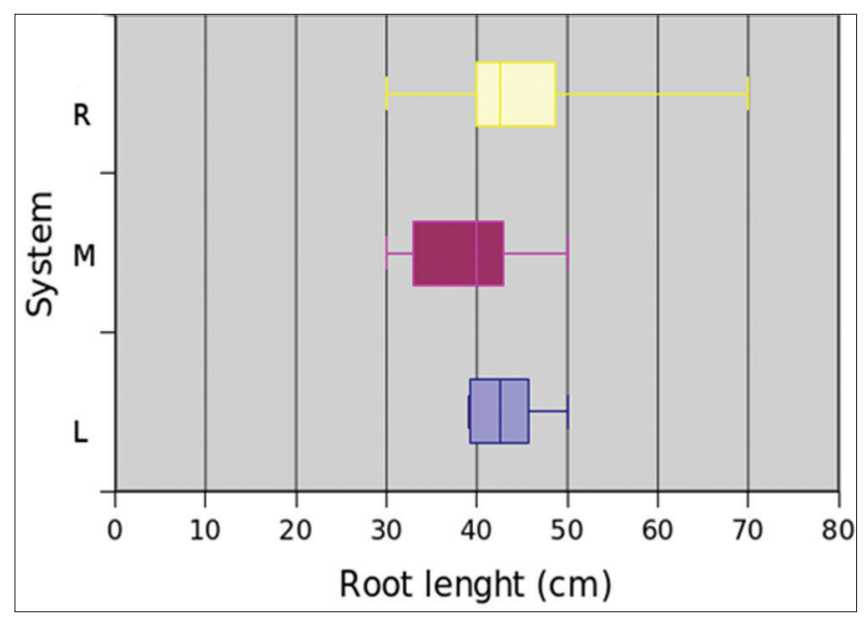

Fig 3. Root length in the system at different nutrients status $(R=$ lowest $(1 / 2 M), M=$ medium, $L=$ highest $(2 M))$. solution), we observe similar picture (Figures 4-8) as we have reported for the roots: more nutrients there are in a solution, smaller is the variability between plants, but here differences are statistically significant $(\mathrm{p}<0,05 \%$, Table 2$)$. Obviously, when nutrients are in excess, plants don't need to compete for their uptake, so variability decreases.

Mobilities of nutrients in the L system are in agreement with values reported by Domingues et al., 2012 and Samarakoon, Weerasinghe, and Weerakkody, 2006 with potassium as the most mobile nutrient.

\section{CONCLUSIONS}

The experiment revealed no significant differences in leaf mineral content and root length between treatments which is opposite to aeroponic experiment performed by Albornoz and Heinrich Lieth, 2015. We have observed much bigger variability of data at the lowest concentration. Similar trend has been observed comparing mobilities: more nutrients there are in a solution, significantly smaller the variability between plants is. Obviously, plants need to compete between each other at lower nutrients availability for their uptake, but not at higher.

\section{ACKNOWLEDGEMENTS}

Authors would like to thank Mrs. Tanja Škvarč for all the help with the analyzes and project AGRIKNOWS, OP SLO - ITA 2007 - 2014 for funding.
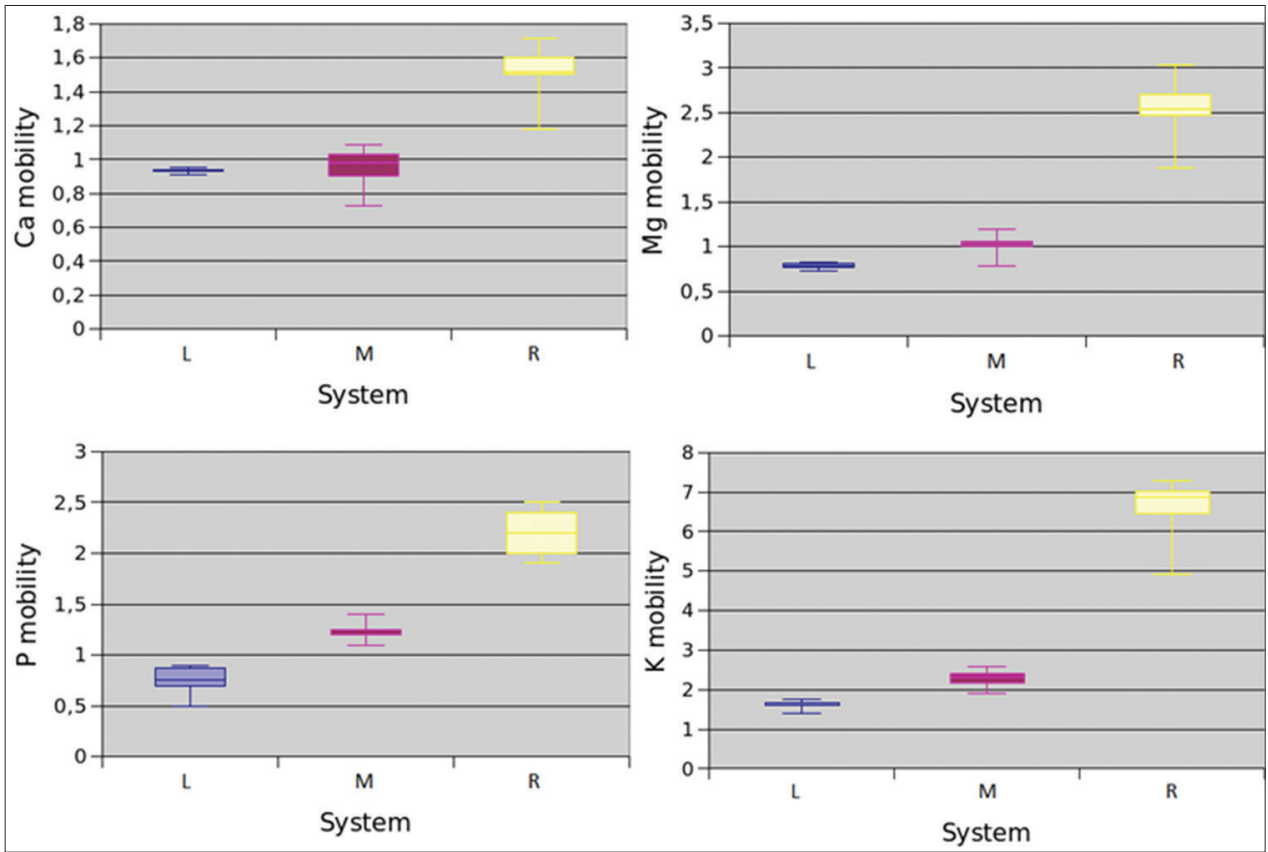

Fig 4-8. Mobility of calcium, magnesium, phosphorous and potassium at different nutrient concentrations in hydroponic solution $(\mathrm{R}=$ lowest $(1 / 2 M), M=$ medium, $L=$ highest $(2 M))$. 
Table 1: Final amount of macro nutrients added into hydroponic solution (ppm)

\begin{tabular}{lccc}
\hline & L & M & R \\
\hline K & 1320 & 660 & 330 \\
Mg & 280 & 140 & 70 \\
Ca & 500 & 250 & 125 \\
$\mathrm{~N}$ & 1340 & 670 & 335 \\
$\mathrm{P}$ & 660 & 330 & 165 \\
$\mathrm{~S}$ & 1560 & 780 & 390 \\
\hline
\end{tabular}

Table 2: Mobility of nutrients in comparison between the systems at different nutrient concentrations in hydroponic solution

\begin{tabular}{ccccccccc} 
& Mn & $\mathbf{C u}$ & $\mathbf{F e}$ & $\mathbf{Z n}$ & $\mathbf{M g}$ & $\mathbf{C a}$ & $\mathbf{K}$ & $\mathbf{P}$ \\
\hline $\mathrm{L}$ & $1,19 \mathrm{a}$ & $0,56 \mathrm{a}$ & $0,39 \mathrm{a}$ & $0,53 \mathrm{a}$ & $0,78 \mathrm{a}$ & $0,93 \mathrm{a}$ & $1,62 \mathrm{a}$ & $0,75 \mathrm{a}$ \\
$\mathrm{M}$ & $0,92 \mathrm{a}$ & $0,63 \mathrm{a}$ & $0,44 \mathrm{a}$ & $0,65 \mathrm{a}$ & $1,02 \mathrm{~b}$ & $0,96 \mathrm{a}$ & $2,28 \mathrm{~b}$ & $1,21 \mathrm{~b}$ \\
$\mathrm{R}$ & $1,05 \mathrm{a}$ & $2,22 \mathrm{~b}$ & $1,99 \mathrm{~b}$ & $1,07 \mathrm{~b}$ & $2,54 \mathrm{c}$ & $1,51 \mathrm{~b}$ & $6,57 \mathrm{c}$ & $2,20 \mathrm{c}$ \\
\hline
\end{tabular}

R: Lowest (1/2 M), M: Medium, L: Highest (2 M)

\section{Author's contribution}

Authors have contributed equally.

\section{REFERENCES}

Albornoz, F. and J. H. Lieth. 2015. Over Fertilization limits lettuce productivity because of osmotic stress. Chil. J. Agric. Res. 75(3): 284-290.

Andriolo, J. L., G. L. da Luz, M. H. Witter, R. S. Godoi, G. T. Barros and O. C. Bortolotto. 2005. Growth and yield of lettuce plants under salinity. Hortic. Bras. 23(4): 931-934.

Azcón, R., E. Ambrosano and C. Charest. 2003. Nutrient acquisition in mycorrhizal lettuce plants under different phosphorus and nitrogen concentration. Plant Sci. 165(5): 1137-1145.

Chen, X. G., C. Gastaldi, M. Y. Siddiqi and A. D. M. Glass. 1997. Growth of a lettuce crop at low ambient nutrient concentrations: A strategy designed to limit the potential for eutrophication. J. Plant Nutr. 20(10): 1403-1117.

Cometti, N. N, G. C. S. Matias, E. Zonta, W. Mary and M. S. Fernandes. 2008. Effects of the concentration of nutrient solution on lettuce growth in hydroponics - NFT system. Hortic. Bras. 26(2): 262-267.

Domingues, D. S., H. W. Takahashi, C. A. P. Camara and S. L. Nixdorf. 2012. Automated system developed to control pH and concentration of nutrient solution evaluated in hydroponic lettuce production. Comp. Electron. Agric. 84: 53-61. DOI: 10.1016/j. compag.2012.02.006.

Enzo, M., G. Gianquinto, R. Lazzarin, F. Pimpini and P. Sambo. 2001. Principi Tecnico-Agronomici della Fertirrigazione e Del Fuori Suolo. Tipografia-Garbin, Padova, Italy.

Harris, D. 1992. Hydroponics: The Complete Guide to Gardening without Soil, Struik, Amsterdam, Netherlands.

Hoagland, D. R., D. I. Arnon. 1950. The Water-Culture Method for Growing Plants without Soil, Circular 347. Agricultural Experiment Station, California

Johnstone, P. R., T. K. Hartz, M. D. Cahn and M. R. Johnstone. 2005.
Lettuce response to phosphorus fertilization in high phosphorus soils. HortScience. 40(5): 1499-1503.

Marschner, H. 1995. Mineral Nutrition of Higher Plants, Gulf Professional Publishing, London.

Maruo, T., Y. Shinohara, M. Iwata and T. Ito. 2002. Effects of nutrient concentration on the absorption of $\mathrm{N}, \mathrm{P}$ and $\mathrm{K}$ by lettuce cultured in NFT system. J. Jpn. Soc. Hortic. Sci. 71: 675-682.

Neumann, G., S. Bott, M. A. Ohler, H. P. Mock, R. Lippmann, R. Grosch and K. Smalla. 2014. Root exudation and root development of lettuce (Lactuca Sativa L. Cv. Tizian) as affected by different soils. Front. Microbiol. 5: 2.

Papathanasiou, F., I. Papadopoulos, I. Tsakiris and E. Tamoutsidis. 2012. Vermicompost as a soil supplement to improve growth, yield and quality of lettuce (Lactuca Sativa L). J. Food Agric. Environ. 10(2): 677-682.

Pisanello, D. 2014. EU regulations on chemicals in foods. In: Chemistry of Foods: EU Legal and Regulatory Approaches, Springer, Heidelberg, Pp. 15-77.

Samarakoon, U. C., P. A. Weerasinghe and W. A. P. Weerakkody. 2006. Effect of electrical conductivity [EC] of the nutrient solution on nutrient uptake, growth and yield of leaf lettuce (Lactuca Sativa L.) in stationary culture. Trop. Agric. Res. 18: 13.

Santos, B. M., Joan, A. D., William, M. S. and James, P. G. 2004. Influence of common lambsquarters (Chenopodium Album) densities and phosphorus fertilization on lettuce. Crop Prot. 23(2): 173-176.

Soundy, P., D. J. Cantliffe, G. J. Hochmuth and P. J. Stoffella. 2001a. Nutrient requirements for lettuce transplants using a floatation irrigation system II. Potassium. HortScience 36(6): 1071-1074

Soundy, P., D. J. Cantliffe, G. J. Hochmuth and P. J. Stoffella. 2001b. Nutrient requirements for lettuce transplants using a floatation irrigation system. I. Phosphorus. HortScience. 36(6): 1066-1070.

Soundy, P., D. J. Cantliffe, G. J. Hochmuth and P. J. Stoffella. 2005. Management of nitrogen and irrigation in lettuce transplant production affects transplant root and shoot development and subsequent crop yields. HortScience 40(3): 607-610.

Schwarz, M. 2012. Soilless Culture Management, Vol. 24. Springer Science \& Business Media, New York.

Smart, F. 2016. Hydroponic Nutrient Solutions. Available from: http://www.smart-Fertilizer.com/articles/hydroponic-NutrientSolutions. [Last accessed on 2016 Jan].

Thorup-Kristensen, K. 1999. Root growth and soil nitrogen depletion by onion, lettuce, early cabbage and carrot. In: International Conference on Environmental Problems Associated with Nitrogen Fertilization of Field Grown Vegetable Crops, Vol. 563. Pp. 201-216.

Thorup-Kristensen, K. 2006. Root growth and nitrogen uptake of carrot, early cabbage, onion and lettuce following a range of green manures. Soil Use Manage. 22(1): 29-38.

Ünlükara, A., B. Cemek, S. Karaman and S. Erşahin. 2008. Response of lettuce (Lactuca Sativa Var. Crispa) to salinity of irrigation water. New Zealand J. Crop Hortic. Sci. 36(4): 265-273.

Vitousek, P. M., R. Naylor, T. Crews, M. B. David, L. E. Drinkwater, E. Holland, P. J. Johnes, J. Katzenberger, L. A. Martinelli, P. A Matson, G. Nziguheba and D. Ojima. 2009. Nutrient imbalances in agricultural development. Science. 324(5934): 1519. 